\title{
Editorial
}

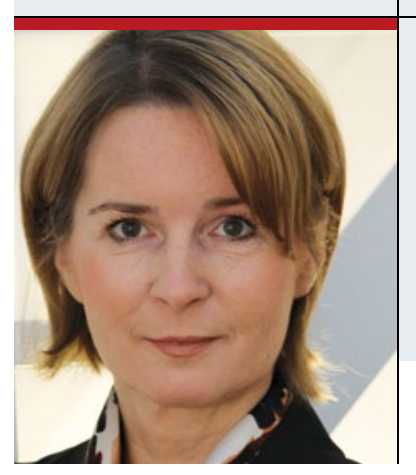

Katja Kupfer Geißler

Chefredaktion

katja.kupfer@springer.com

facebook.com/heilberufe

\section{Springer goes Pflege}

$\mathrm{H}$ aben Sie das neue Logo „Springer Pflege“ auf dem Titel von HEILBERUFE gesehen? Vermutlich fragen Sie sich jetzt, was das mit Ihnen $\mathrm{zu}$ tun hat? Klingt nach Eigenwerbung. JA! Denn: Wir sind stolz darauf! Für das Team Pflege bedeutet dieses Bekenntnis des Verlages zur Pflege nicht nur eine Aufwertung unserer Tätigkeit in der Redaktion und der Kongressabteilung, sondern auch Ihrer Arbeit. Für Sie als Pflegende wird es zukünftig ein Mehr an Leistung, an Qualität, an Fortbildung bedeuten. Grund genug jedenfalls, unseren Geschäftsführern ein paar Fragen zu stellen nach dem Wieso und Warum dieser Entscheidung. Das Interview mit Joachim Krieger und Falk Miekley lesen Sie auf Seite 7.

Im vergangenen Jahr hat unser PflegeKolleg zu Prophylaxen so eine große Resonanz erfahren, dass wir uns entschlossen haben, Ihnen mit Informationen zur Aspiration, zu Kontrakturen und zur Intertrigo eine Fortsetzung anzubieten: Die Fortbildung „Prophylaxen II“ finden Sie ab Seite 9.

Bei Pflegenden wird ja gern pauschal vom „Helfersydrom" gesprochen. Natürlich leidet nicht jede
Pflegekraft, die ihren Beruf mit Hingabe ausübt, unter einem Helfersyndrom. Was aber, wenn tatsächlich ein krankhafter Umgang mit dem Patienten vorliegt und Pflege zur Selbstaufgabe führt? Patrick Fehling beschreibt in seinem Beitrag „Wann ist Helfen krankhaft?" (Seite 44), dass Pflegende durch eine derartiges Verhalten nicht nur sich selbst, sondern letztlich auch ihren Patienten schaden. Zum Glück haben er und Interviewpartnerin Barbara Messer ein paar Tipps für Sie parat.

\section{Viel Spaß beim Fortbilden mit HEILBERUFE}

Ihre

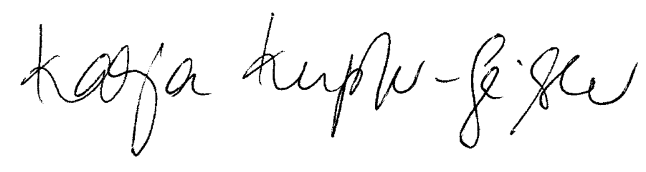

Anregungen, Wünsche, Fragen oder Lob? Scheiben Sie uns: katja.kupfer@springer.com

\section{INFO}

\section{Deutscher Krebskongress 2016}

Vom 24. bis 27. Februar findet im CityCube Berlin der größte Fachkongress zur Krebsdiagnostik und -therapie im deutschsprachigen Raum statt. Erwartet werden mehr als 10.000 Teilnehmer - auch aus der onkologischen Pflege. Vor dem Hintergrund neuer zielgerichteter Therapien wird eine fachliche Begleitung und Beratung der Patienten durch Pflegende immer wichtiger. Auch in unserem PflegeKolleg "Krebsmedizin heute" (ab Seite 23) greifen wir aktuelle Themen aus der Onkologie auf. 